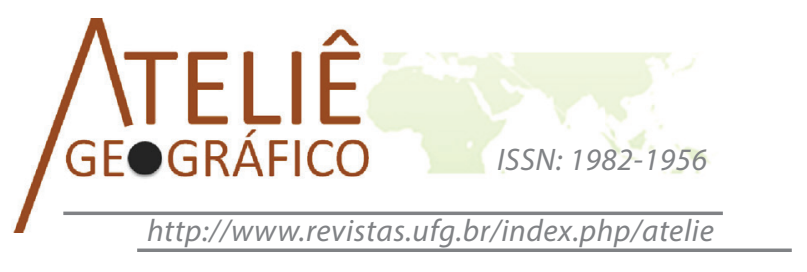

\title{
Território digital: detecção dos padrões espaciais da desigualdade socioterritorial do município de Aparecida de Goiânia - GO
}

\author{
Digital territory: detection of spatial patterns of socio- \\ -territorial inequality of Aparecida de Goiânia - GO
}

\section{Territorio digital: detección de patrones espaciales de la desigualdad socioterritorial de la ciudad de Aparecida de Goiânia - GO}

\author{
Fabrizia Gioppo Nunes \\ Universidade Federal de Goiás \\ fabrizia.iesa.ufg@gmail.com
}

\begin{abstract}
Resumo
A presente pesquisa está atrelada ao procedimento teórico-metodológico da distribuição espacial, de índices censitários da desigualdade socioterritorial, do município de Aparecida de Goiânia. Após o delineamento das utopias que indicam a exclusão/inclusão social, foram confeccionados mapas coropléticos, que medem o grau de autocorrelação espacial, destes índices. Tais mapas foram gerados a partir da aplicação da técnica de Análise Espacial, em plataforma de Sistema de Informação Geográfica (SIG) e, tendo como premissa o conceito de território digital. Dos resultados obtidos foi testada como a técnica de análise exploratória, representada pelos mapas e diagramas de espalhamento de Moran, pode ser útil na identificação de áreas de clusters de exclusão/inclusão social. Como indicativo final, pode-se verificar que das variáveis testadas, a proporção de domicílios com precária instalação sanitária e de chefes de famílias na linha da pobreza, são os dois índices que mais contribuem para a exclusão social no município.
\end{abstract}

Palavras-chave: cartografia, dados censitários, autocorrelação, dinâmica espacial, intraurbano.

\footnotetext{
Abstract

The present research is coupled with the technical methodological procedure of spatial distributions, socio-territorial inequalities census data of the municipality of Aparecida de Goiânia. After the outlining of the utopias that signal social exclusion/
} 
inclusion, cloropleth maps were elaborated; these measure the spatial correlation grades from the indexes. Such maps were generated by de application of the Spatial Analysis technique, utilizing the Geographic Information System (GIS) platform and having as premise the concept of digital territory. From the results obtained, was tested how the technique of exploratory analysis, represented by maps and diagrams of Moran Scatterplot, could be useful on the identification of clusters areas of social exclusion/inclusion. As a final indicative, it was verified that from the variants considered, the percentage of domiciles with precarious sanitary installations and head of households in poverty line are the ones that most contribute to the social exclusion of the city.

Keywords: mapping, census data, autocorrelation, spatial dynamics, intra-urban.

\begin{abstract}
Resumen
La investigación es vinculada al procedimiento teórico y metodológico de la distribución espacial de los índices del censo de la desigualdad socioterritorial, de la ciudad de Aparecida de Goiânia. Después de la selección de las utopías que indican la exclusión/inclusión social, fueron hechos mapas coropleticos, que miden el grado de autocorrelación espacial, estos índices. Estos mapas fueron generados a partir de la aplicación de técnicas de Análisis Espacial en la plataforma de Sistema de Información Geográfica (GIS) y, teniendo como premisa el concepto de territorio digital. De los resultados fue probado como la técnica de análisis exploratorio, representada por los mapas y gráficos de dispersión de Moran, puede ser útil en la identificación de áreas de agrupaciones de exclusión/inclusión. El resultado final, se puede observar que de las variables analizadas, el porcentaje de domicilios pobres con precaria instalación de lavabo y los jefes de familia en línea de la pobreza, son los dos índices que más contribuyen a la exclusión social de la ciudad.

Palabras clave: cartografía, datos del censo, autocorrelación, dinámicas espaciales, intraurbano.
\end{abstract}

\title{
Introdução
}

Aparecida de Goiânia como a maioria das cidades de regiões metropolitanas brasileiras é configurada por um cenário esculturador de "bolsões" de pobreza. Imagem esta, derivada da própria trajetória histórica de ocupação do município, da conurbação com sua capital e do processo de metropolização do entorno de Goiânia. Hoje, o município reproduz a lógica comum dos apêndices periféricos brasileiros. Em seu perímetro intraurbano encontra-se espaços segregados, altamente diferenciados e desprovidos de recursos básicos necessários a qualidade de vida digna da população.

É importante frisar que a qualidade de vida é assegurada pela Constituição Brasileira. Em termo de Diretrizes Gerais, o $2^{\circ}$ artigo do Estatuto da Cidade (2009), prevê a garantia do direito as cidades sustentáveis. Direito este assegurado por uma gestão democrática de cooperação do governo, da iniciativa privada e demais setores da sociedade, no processo da urbanização para a promoção do desenvolvimento socioeconômico. Logo, a socioeconomia deve ser pensada de forma a atender aos interesses coletivos da sociedade, na garantia da equidade de bens e da qualidade de vida urbana. 
Ao modelarmos os territórios digitais urbanos com a representação e revelação dos "territórios invisíveis", ou seja, dos espaços intraurbanos altamente diferenciados, definimos a particularidade de cada lugar dentro da visão da distribuição da equidade de bens e da qualidade de vida urbana. Esta visão mensurada é indispensável para formulação de gestões públicas, cuja distribuição de serviços e benefícios, seja coerente com as necessidades da população. Nesta lógica, Câmara et al. (2005) parafraseiam Milton Santos (2000), quando apontam que "o território é dado essencial da condição da vida cotidiana”, enfatizando os autores a necessidade de usar o território digital para retomar o controle dos territórios reais.

Em termos de territórios reais Vitte (2009,p.111), chama atenção para o emprego desta categoria de análise, na questão da qualidade de vida. Para o autor o território é entendido como o produto de um processo político e social, portanto histórico, e revelador das condições de vida e da maior ou menor presença do poder público na vida das pessoas e de seus lugares.

No âmbito desta questão, os modelos de representação computacional, tem abordado sobre o paradigma de elaboração dos instrumentos de gestão pública urbana brasileira, consubstanciados na construção do conceito de território digital. Este deve buscar aspectos cada vez mais complexo da realidade urbana, ou seja, dos territórios reais, mediada por técnicas computacionais da geoinformação, colocando essas práticas efetivamente à serviço da sociedade.

É focalizado na aplicação desta temática, que o presente estudo visa avaliar e cartografar os padrões de distribuição espacial da desigualdade socioterritorial, do município de Aparecida de Goiânia. Para tanto, adotou-se como referência métodos e técnicas de análise espacial, no delineamento de padrões de indicadores de exclusão/ inclusão social. Como foco conceitual, foi adotado o procedimento teórico-metodológico de aplicação de ferramentas de geoprocessamento, voltadas à modelagem do território digital urbano.

Nesta perspectiva, a ontologia urbana direcionada à questão da organização do espaço de Aparecida de Goiânia, por intermédio da representação do território digital urbano, torna necessária, à medida que os elementos estruturantes que lhe atribuem à configuração socioterritorial, estão atrelados as suas funções sociais. Surge aqui, o feedback para a questão: como combater a exclusão social, sem saber onde estão os excluídos? Neste termo a representação computacional, formula-se como um elemento chave para compreender a distribuição espacial, das distintas camadas da população aparecidense.

É importante ressaltar que o termo território digital é entendido como o recorte espacial de captura e representação de dados quantitativos (GENOVEZ et al., 2007, p. 64). A identificação das variáveis quantitativas, do aspecto de vida da população de Aparecida de Goiânia, foram extraídas de informações censitárias do IBGE. Essas informações visam caracterizar aspectos relacionados às questões de autonomia de renda, desenvolvimento urbano, qualidade ambiental, conforto de vida e equidade. 


\section{O espaço socioterritorial de Aparecida de Goiânia - Breve análise}

A transformação do espaço aparecidense foi um processo heterogêneo calcado na metropolização da região de entorno de Goiânia. Segundo Santos (2008), a urbanização de Aparecida de Goiânia originária das distintas facetas sociais e econômicas, que modelam o seu espaço intraurbano, está atrelada ao enredo histórico de apropriação do município. Para o autor, este processo de ocupação, pode ser dividido em quatro fases evolutivas:

(I fase) 1922 a 1963 - De um estágio de núcleo isolado à constituição de espaços segregados; (II fase) de 1963 a 1980 - Da estruturação do espaço metropolitano à produção de periferias expandidas e segregadas; (III fase) de 1980 a 1990 - Marcada pela consolidação da segregação socioterritorial, advinda da intensificação demográfica e; (IV fase) de 1990 aos dias atuais - Constituição de uma região geral, multifuncional, integrada da cidade (SANTOS, 2009).

Ainda em relação a fase atual Cirqueira Pinto (2009), assinala que o efeito da periferização da cidade de Goiânia, faz com que Aparecida de Goiânia apresente um cenário de cidade fragmentada, com áreas compartimentadas, altamente especializadas em função das características derivadas de suas atividades multifuncionais. Estas atividades estão direcionadas a estruturação interna de seu centro histórico, de seu comércio local e com a capital e das áreas periféricas da cidade, marcadas pela ausência de infraestrutura básicas e de equipamentos públicos adequados. Desta forma, na visão do autor:

Aparecida de Goiânia se organiza estabelecendo múltiplas funcionalidades com a sua capital, parecendo que existem várias cidades dentro de uma só, que pouco se relaciona consigo mesma e muito se relaciona com Goiânia (CIRQUEIRA PINTO, 2009, p.103).

Com a construção da capita do Estado, algumas glebas do que hoje é o território de Aparecida de Goiânia, foram transferidas aos empreiteiros como parte do pagamento pelos serviços prestados em Goiânia. Na década de 50 inicia-se o processo de parcelamento das terras de Aparecida, denominada ainda, como distrito de Goiânia.

Com a construção de Brasília na década de 60 , o estado de Goiás sofre um significativo movimento de migração. Goiânia começa a sentir a pressão do processo de ocupação. Para resguardar um ambiente urbano qualificado da capital é aprovada a Lei Municipal no 4.526, de 1972, que defini regras restritivas de uso e ocupação do solo.

Como alternativa, o Estado passa a promover a doação de áreas públicas à especulação imobiliária e assentamentos populares, em regiões circunvizinhas a capital, agravando ainda mais o quadro de ocupação urbana de Aparecida de Goiânia, na décadas de 1980 e 1990.

Neste status de cidade "periferia" e impulsionada pelo poder especulativo imobiliário, surgem os denominados loteamentos espraiados, em meio a um território sem infraestrutura básica para a fixação da população mais pobre, proveniente tanto da capital como do próprio município (BOAVENTURA e ASSUNÇÃO, 2013, p. 215). 
Hoje com uma população majoritariamente urbana e, pela sua proximidade com a capital do estado, Aparecida de Goiânia configura-se como um cidade conturbada e dormitória. De uma população de 455.657 habitantes estimada no último censo demográfico, desta, 121.408 aparecidenses se deslocam para outros municípios para trabalhar e/ou estudar, ou seja, 26,6\% de sua população (IBGE-Cidades, 2010).

Nesta perspectiva, os dados apresentados no diagnóstico do Plano Diretor da Cidade (PD, 2014), revelam que o município atualmente possui $67 \%$ de sua área dentro do perímetro urbano, sendo apenas $33 \%$ relativa a área rural. Foi este elevado crescimento demográfico urbano, associado as características de ocupação e organização territoriais específicas, que estimulou a formação de centralidades de complexidades diferentes.

Estas centralidades estão fomentadas ao longo de eixos viários da área conurbada com a capital (Av. Rio Verde, Anel Viário e Rodovia GO-040), de vias que conectam loteamentos implantados de forma segregada e, em vias locais de bairros caracterizados pelo alto grau de segregação. Assim, o município matem a lógica caótica em determinadas áreas da cidade, porém, estas áreas encontram-se contrabalançadas pelos setores especializados e pelas centralidades comerciais (CIRQUEIRA PINTO, 2009).

O próprio PD (2014), considera as centralidades como o espaços sobre os quais há presença de certa diversidade de atividades econômicas e comunitárias, que se desenvolveram de forma espontânea. Assim, o poder púbico administrativo dentro do caráter de ordenador do território institui as macros-regiões administrativas, com o intuito de facilitar a orientação das políticas públicas locais. Este macrozoneamento subdivide o município em 11 zonas, distribuídas entre seus perímetros urbano e rural, além da Área de Preservação Ambiental - APA da Serra das Areias (Figura 1).

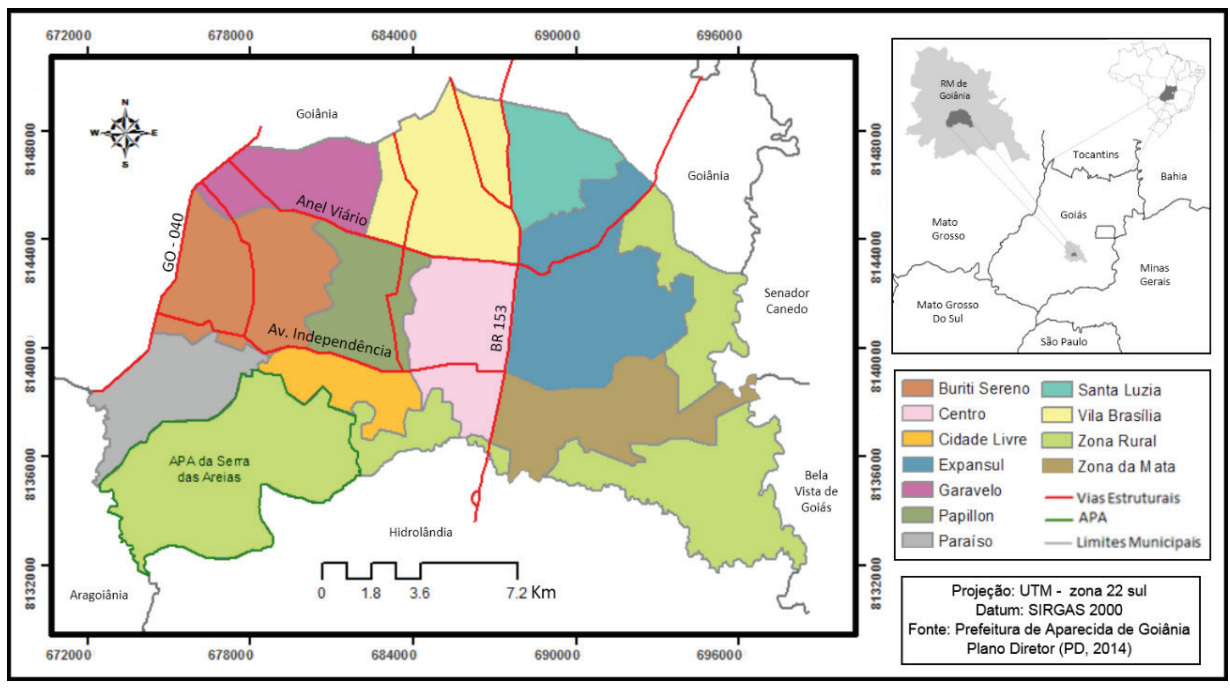

Figura 1. Localização das regiões administrativas do município de Aparecida de Goiânia. 
As regiões de Garavelo, Santa Luzia e Vila Brasília, originárias da conurbação com a capital, são habitadas em geral pela população de melhor poder aquisitivo. O seu grau de urbanização é mais complexo, pois são regiões que contam com boa quantidade de equipamentos, infraestrutura instalada e elevada densidade habitacional. Garavelo possui forte dinamismo nos setores de comercio e serviço, atraindo consumidores locais e também de municípios vizinhos. Já a região Central, composta pelo Centro Tradicional Histórico de Aparecida de Goiânia e pelos seus bairros de entorno, é desenvolvida pelo setor de prestação de serviços púbicos e por algumas atividades comerciais.

Como setores periféricos e consequentemente menos desenvolvidos economicamente, o município possui as regiões de Paraiso, Buriti Sereno, Cidade Livre, Zona da Mata e Expansul. Caracterizadas por espaço segregados, de população de baixa renda, constituídas por bairros de ocupação majoritariamente residencial, provenientes em grande parte de assentamentos e loteamentos de programas habitacionais. A região conhecida como Expansul, além de apresentar alguns loteamentos residenciais, comporta também funções urbanas e periurbanas específicas com os polos industriais, aterro sanitário, cemitérios, estação de tratamento de esgoto (ETE) e áreas de extração mineral (Figura 2).

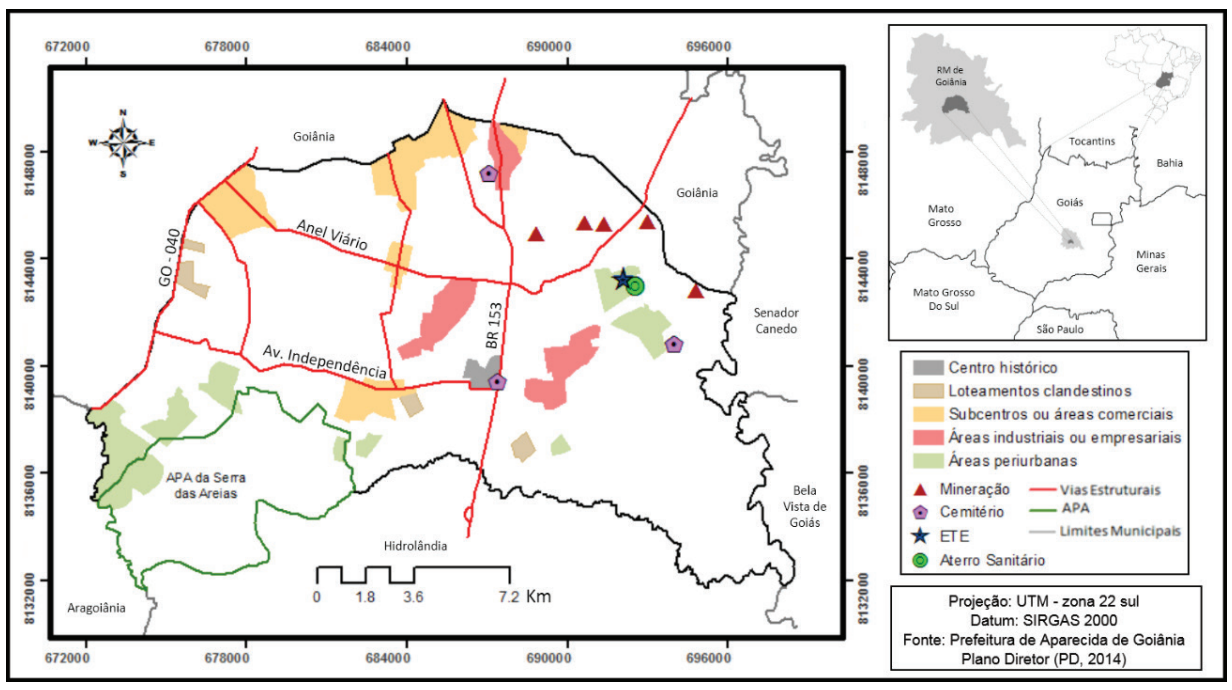

Figura 2. Elementos espaciais fragmentados de funções urbanas e periurbanas específicas.

Por fim a região de Papillon é formada por residências unifamiliares, de médio poder aquisitivo, e por alguns conjuntos de edifícios. No seu Anel Viário, juntamente com a região Central do município, conta com a presença do principal polo industrial do município. 
Quanto a questão da infraestrutura básica, vale atentar-se, para o fato de que, Aparecida de Goiânia ainda hoje é considerada como um município bastante carente em saneamento básico. No último censo é verificado que $72,8 \%$ de suas residenciais possuem saneamento semi-adequado, sendo somente $26,8 \%$ com sistema de saneamento totalmente adequado, por via de abastecimento de água e coleta de esgoto por rede geral (IBGE-Cidades, 2010). Mais de 76.832 pessoas são consideradas pobres, pois recebem até meio salário mínimo, sendo que, dentre estas, a proporção da taxa de pobreza que representa o percentual de pessoas pobres, em relação a população total do município é na ondem de $23 \%$.

\section{Território digital e análise espacial}

Os Territórios Digitais são as diferentes representações da realidade geográfica num ambiente computacional, obtidas por meio de Sistemas de Informação Geográfica (SIG). Não são apenas mapas coloridos, mas sim expressões quantitativas, dos diferentes processos físicos e socioeconômicos. Vão além da criação e elaboração de mapas, fazendo uso de modelos lógicos, estruturas de dados, algoritmos e linguagens computacionais (ROMAN et al., 2007, p.35).

Para Câmara et al. (2005, p.2) a ideia norteadora é o conceito de representação computacional, que busca capturar as diferentes dimensões do espaço geográfico, estabelecendo uma correspondência entre o mundo real e sua representação digital. Metodologicamente os dados utilizados para construir os Territórios Digitais, podem ser divididos em três categorias: (a) dados do meio físico que descrevem os diversos componentes da natureza e da paisagem; (b) dados cadastrais que descrevem os elementos da apropriação do território, com ênfase no espaço produzido e nos limites estabelecidos em contratos legais (delimitações territoriais políticas-administrativas) e; (c) dados socioeconômicos, representativos do tipo de ocupação do território, indicando os diferentes aspectos da condição de vida da população (dados censitários).

Quando se trata de modelagem computacional de natureza socioeconômica, os autores supracitados (2005, p.4) apontam a necessidade de critérios metodológicos que abordem conceitos sociológicos, utilizáveis em estudos quantitativos, no intuito de subsidiar políticas públicas territoriais. Estes conceitos devem ser passíveis de serem associados a propriedades mensuráveis, medidas no território, permitindo a diferenciação entre a população estudada, sendo uma abordagem direcionada ao estudo das desigualdades sociais.

Nesta questão Humacata (2010, p.138) destaca que as técnicas de Análise Espacial, contribuem efetivamente para a compreensão dos modelos de regionalização urbana, das desigualdades socioespacial. O autor salienta a importância de que a componente espacial detém certos padrões de distribuição, considerando a região geográfica como um conjunto de partes com características semelhantes, denominadas de clusters. 
Nesta concepção a Análise Espacial é definida como o estudo, a exploração e a modelagem de processos que se expressam por meio de sua distribuição no espaço. Seu propósito é mensurar propriedades e seus relacionamentos, levando em conta a localização espacial do fenômeno em estudo (CÂMARA et al., 2004).

Quando se trata de técnicas espaciais direcionadas a delimitações territoriais, essas são apresentadas em forma de índices que medem a autocorrelação espacial. Tais resultantes são derivadas de diagramas de espalhamento e mapas coropléticos, auxiliando na identificação de agrupamentos de elementos, cujos atributos possuem valores altos e baixos, áreas de transição e casos atípicos (KREMPI, 2004).

É importante salientar que a técnica de Análise Espacial permite descrever a distribuição das variáveis em estudo, identificar observações atípicas não só em relação ao tipo de distribuição de cada unidade, mas também em relação aos seus vizinhos, buscando a existência de padrões, áreas de clusters, na distribuição espacial dos elementos em análise (ANSELIN, 1998).

Neste estudo, a análise espacial teve por base as técnicas de análise exploratória, derivadas do índice de Moran Global e Local. A referida técnica foi apoiada no procedimento metodológico elaborado pelo Centro de Estudos das Desigualdades Socioterritoriais (Cedest), em parceria com o Instituto Nacional de Pesquisa Espacial (Inpe), Núcleo de Seguridade e Assistência Social (PUC-SP) e Instituto de Estudos Formações e Assessoria em Políticas Sociais (Polis), (GENOVEZ et al., 2007).

A metodologia indicada modela os índices de exclusão/inclusão social dentro do conceito de heterotopia, que considera a função de quatro diferentes utopias: autonomia, desenvolvimento humano, qualidade de vida e equidade. A disparidade socioeconômica é revelada em diagramas de dispersão, agrupados em áreas de clusters com: o quadrante (Q1) indicando valor alto do atributo analisado e média de seus vizinhos também elevada; Q2 indicando valor baixo do atributo e média de seus vizinhos também baixa; além dos quadrantes (Q3 e Q4) das áreas de transição, que considera a média dos valores dos setores censitários vizinhos, com comportamento distinto.

Desta forma, comparou-se nos diagramas de dispersão a relação estatística que considera o desvio de cada setor censitário observado, em relação à média global $(\mathrm{Z})$ normalizada, e a média de seus setores vizinhos (WZ), também normalizadas e tendo como princípio básico, que existe uma maior interação espacial entre regiões vizinhas, do que entre regiões distantes umas das outras.

As informações dos setores censitários, foram obtidas a partir dos dados disponibilizados pela equipe de Transferência de Tecnologia do Centro de Estudos da Metrópole-CEM. Os arquivos vetoriais no formato shapefile contêm os geocódigos das unidades territoriais, acompanhados por tabelas de atributos, de informações coletadas do último censo demográfico do IBGE (2010).

Para a análise, foram selecionadas variáveis do "universo" de representação da exclusão/inclusão social, as quais foram agregadas à base cartográficas a partir do 
geocódigo de cada setor censitário (Codsetor). O Quadro 1 representa os indicadores de exclusão/inclusão social, adaptados de acordo com a oferta de dados dos setores censitários para o município e, objetivando, uma escala de análise à este nível de detalhe.

Quadro 1. Parâmetros indicadores da exclusão/inclusão social

\begin{tabular}{|c|c|c|}
\hline Utopia & Índices & Indicadores (lexi) \\
\hline \multirow{2}{*}{$\begin{array}{l}\text { Autonomia de } \\
\text { Renda }\end{array}$} & \multirow{2}{*}{$\begin{array}{l}\text { Precária condição de } \\
\text { sobrevivência }\end{array}$} & $\begin{array}{l}\text { ChFLinhP - proporção de chefes de família } \\
\text { na linha da pobreza (ganho de até } 1 / 2 \text { salários } \\
\text { mínimos) }\end{array}$ \\
\hline & & $\begin{array}{l}\text { ChFBaxP - proporção de chefes de família } \\
\text { abaixo da linha da pobreza (pessoas responsáveis } \\
\text { sem rendimento) }\end{array}$ \\
\hline \multirow{4}{*}{$\begin{array}{l}\text { Desenvolvimento } \\
\text { Humano }\end{array}$} & Longevidade & Long - proporção da população acima de 70 anos \\
\hline & Estímulo educacional & $\begin{array}{l}\text { AfTard - proporção de alfabetização tardia } \\
\text { (pessoas de } 10 \text { a } 14 \text { anos) }\end{array}$ \\
\hline & Escolaridade precária & EscPrec - proporção de pessoas não alfabetizadas \\
\hline & $\begin{array}{l}\text { Desenvolvimento } \\
\text { educacional }\end{array}$ & $\begin{array}{l}\text { DEduc - proporção de chefes de família não } \\
\text { alfabetizados }\end{array}$ \\
\hline \multirow{5}{*}{$\begin{array}{l}\text { Qualidade de } \\
\text { Vida }\end{array}$} & \multirow{3}{*}{ Qualidade ambiental } & $\begin{array}{l}\text { AAPrecp - proporção de domicílios com precário } \\
\text { abastecimento de água }\end{array}$ \\
\hline & & $\begin{array}{l}\text { ISPrecp - proporção de domicílios com precária } \\
\text { instalação sanitária (esgoto) }\end{array}$ \\
\hline & & $\begin{array}{l}\text { PTLixo - proporção de domicílios com precário } \\
\text { tratamento do lixo (sem coleta de lixo) }\end{array}$ \\
\hline & \multirow{2}{*}{ Conforto domiciliar } & $\begin{array}{l}\text { DHab - densidade habitacional (proporção de } \\
\text { domicílios com } 6 \text { ou mais moradores) }\end{array}$ \\
\hline & & $\begin{array}{l}\text { DoPV - proporção de domicílios sem } \\
\text { pavimentação }\end{array}$ \\
\hline Equidade & Equidade feminina & MChF - proporção de mulheres chefes de família \\
\hline
\end{tabular}

Fonte: adaptado de Genovez et al. (2007).

Para um panorama da metodológica da análise exploratória em ambiente SIG, o fluxograma ilustrado na Figura 3, apresenta as etapas que foram adotadas para a definição de áreas de clusters de exclusão/inclusão social. 


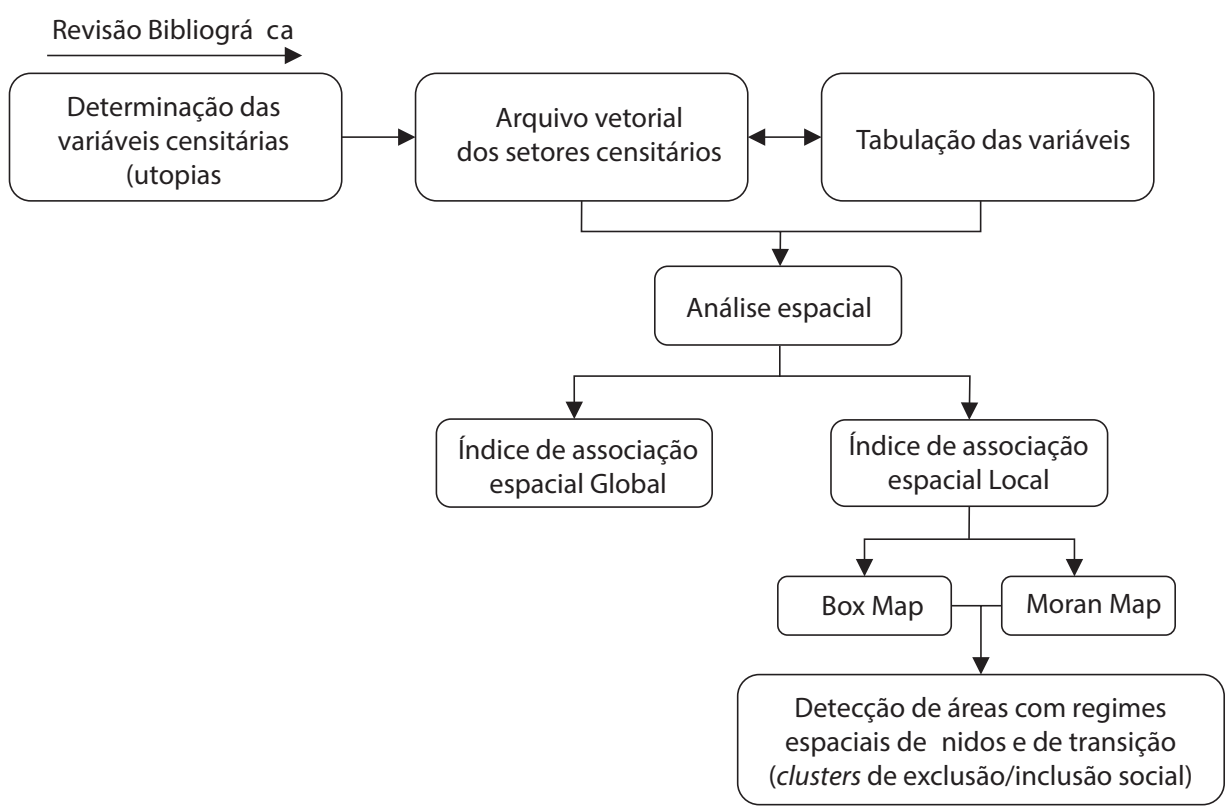

Figura 3. Fluxograma do procedimento teórico-metodológico desenvolvido.

\section{Indicadores intraurbanos da segregação e desigualdade socioterritorial}

Os resultados da análise exploratória aplicada pela técnica de SIG, revelam que Aparecida de Goiânia possui aglomerados de fragmentos censitários com regimes espaciais definidos, juntamente com áreas de transição, indicadoras do comportamento estatístico das utopias analisadas. Como resposta direta à esta análise obteve-se os mapas e diagramas das figuras 4 a 7, que reúnem os índices de autocorrelação espacial, Global e Local, das utopias analisadas.

Os resultados do índice Global de Moran mensurado na escala que quantifica a exclusão/inclusão social, em um linear que varia de $-1 \mathrm{a}+1$, demostram que os indicadores de ISPrecp, proporção de domicílios com precária instalação sanitária, igual a 0,517 e ChFLinhP, proporção de chefes de família na linha da pobreza, igual 0,449 foram as duas variáveis que menos apresentaram correlação espacial, ou seja, as que possuem maior disparidade do índice de exclusão/inclusão. Em compensação, a variável PTLixo com baixa proporção de domicílios com precário tratamento do lixo, igual a $-0,003$, apresenta-se bastante homogênea, ou seja, com uma hipótese quase nula de aleatoriedade espacial. Esta variável é a que menos contribuiu para a exclusão social.

Os diagramas de dispersão de Moran representados para cada indicador, corroboram também para esta análise (Figuras 4 a 7). Observa-se que os indicadores de ISPrecp e ChFLinhP, apresentam maior concentração de setores censitários no quadrante Q1, indicando um Alto-Alto índice de exclusão. No caso da variável PTLixo, os setores censitários em maioria concentram-se no quadrante Q2, caracterizando um Baixo-Baixo 
índice do parâmetro em análise, ou seja, de exclusão. Vale lembrar que quando mais próximo de uma reta, ou seja, mais próximo tiverem um ponto representativo do outro, maior será a tendência de correlação espacial entre os setores censitários da variável avaliada.

As informações contidas na Figura 4, mostram os padrões espaciais das variáveis de autonomia de renda e longevidade, representadas pelo indicador local de autocorrelação espacial, Box Map e Moran Map. No Box Map do indicador ChFLinhP, verifica a presença de clusters de elevado índice de chefes de família na linha da pobreza concentrados nas regiões da Zona Rural, Zona da Mata, Paraíso, Papillon e na porção norte das regiões Central, Buriti Sereno e Expansul.

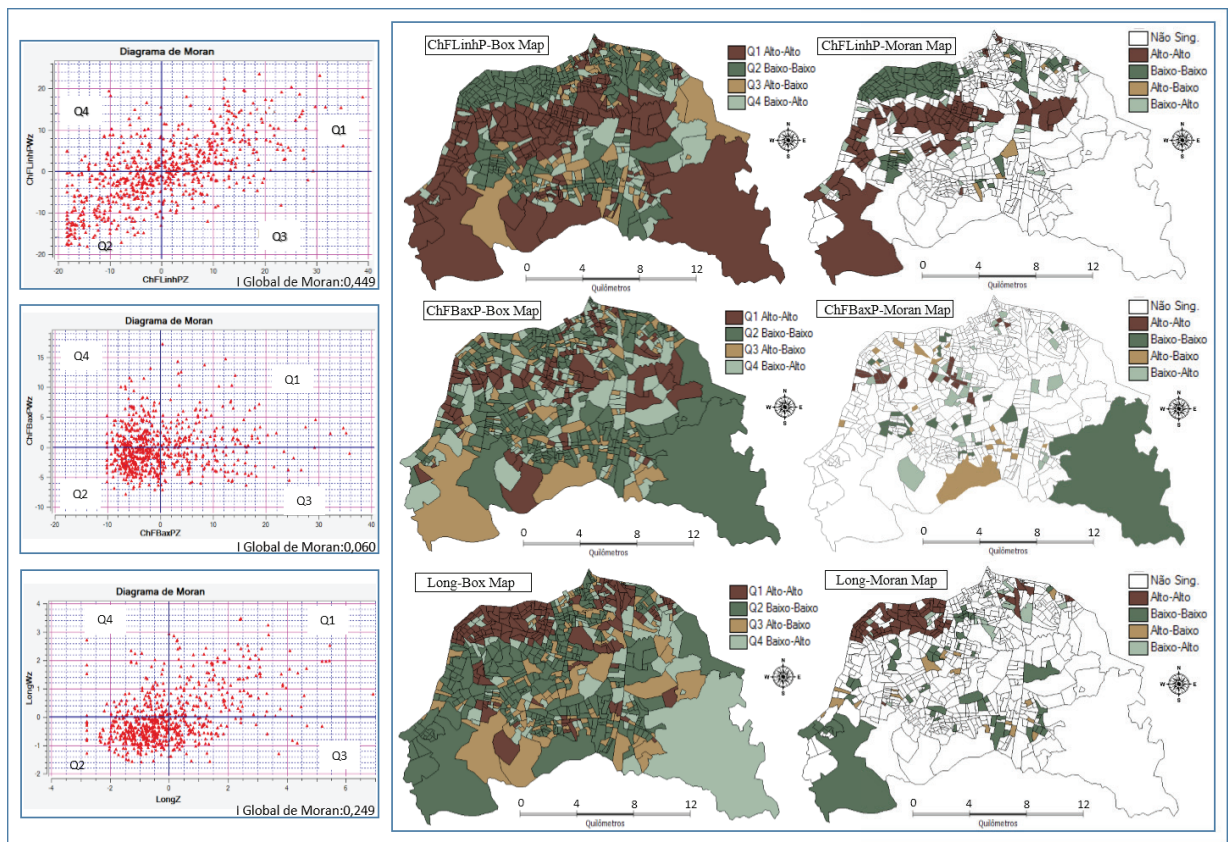

Figura 4. Índices de autocorrelação espacial dos indicativos da autonomia de renda e longevidade.

No indicativo de ChFBaxP são verificados alguns fragmentos de setores censitários, com elevada proporção de chefes de família abaixo da linha da pobreza nas regiões de Buriti Sereno, Papillon, Central, Paraíso e Expansul. Já para a variável longevidade (Long) é verificada apenas uma pequena área de cluster, de inclusão social, pertencente as regiões de Garavelo e Vila Brasília, com apenas alguns fragmentos censitários apresentado elevado percentual de pessoas acima dos 70 anos de idade.

Nos Moran Map são apontados somente os dados considerados estatisticamente significativos. Nestes produtos cartográficos ilustrados na Figura 4, é visível a presença 
de clusters significativos de exclusão/inclusão social, em locais específicos do município. Como áreas relevantes, são apontados os clusters significativamente determinantes, para a exclusão social na variável ChFLinhP presentes nas regiões de Papillon, Central e Buriti Sereno. Na região de Paraíso e na APA da Serra das Areias é observado também, "bolsões" de significância Alto-Alto para a variável ChFLinhP e Baixo-Baixo para a longevidade, demonstrativos de áreas de exclusão.

$\mathrm{Na}$ utopia de desenvolvimento humano, que envolve aspectos educacional e de escolaridade, os Box Map da Figura 5, evidenciam nas variáveis de alfabetização tardia (AfTard) e de pessoas não alfabetizadas (EscPrec), clusters de Alta-Alta e AltaBaixa exclusão social em quase todas as regiões administrativas, excetuando-se a porção extremo norte e noroeste do município, nas regiões de Garavelo e Vila Brasília.

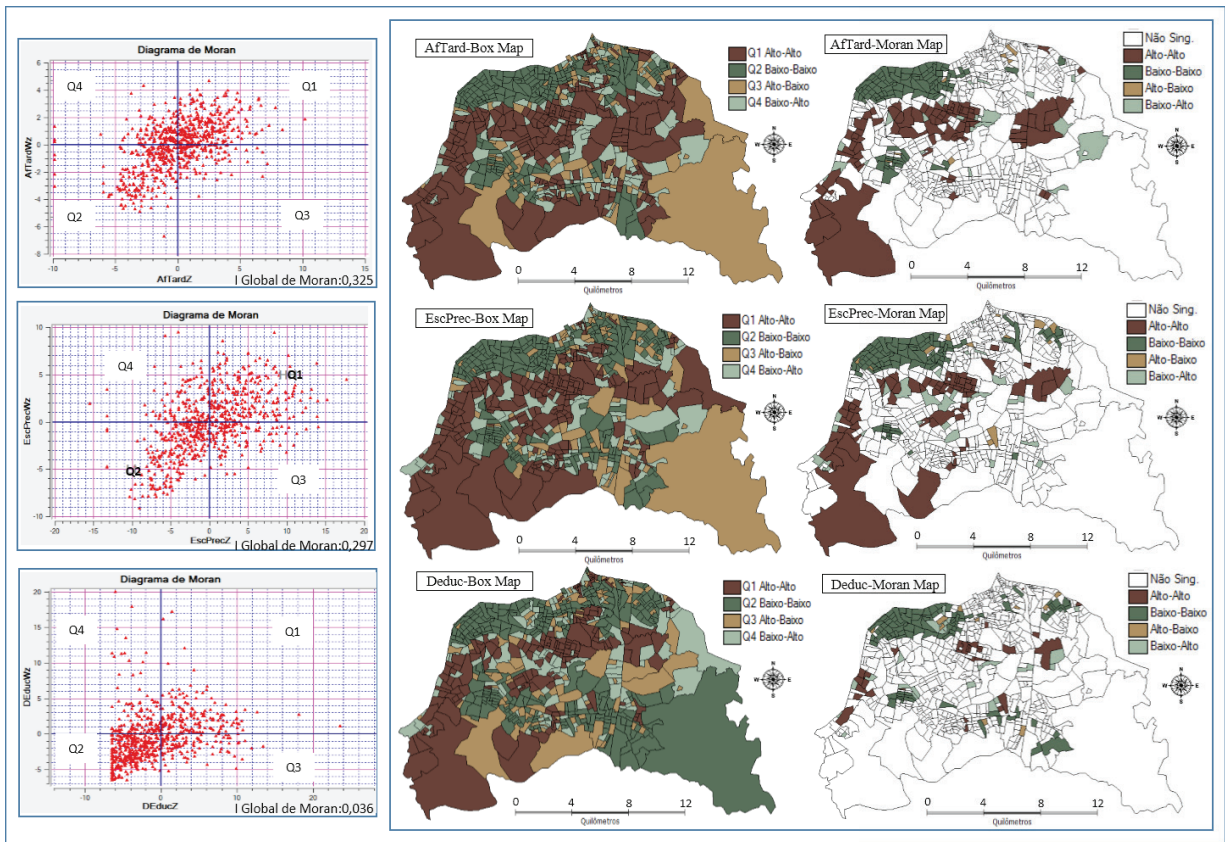

Figura 5. Índices de autocorrelação espacial dos indicativos do desenvolvimento humano educacional e escolar.

Em contrapartida a variável de chefes de família não alfabetizados ((DEduc), apresenta Baixa-Baixa exclusão social dominante, nas regiões norte, centro e sudeste do município. Esta variável possui setores relevante de Alta-Alta exclusão, à sudoeste do município, abrangendo determinadas porções das regiões da Zona Rural, Paraíso, Papillon e Central. Como resultante dos Moran Map da Figura 5, são verificados clusters de alta exclusão social estatisticamente significativos, nos índices de AfTard e EscPrec, 
localizados na porção central e a sudoeste do município e, de baixa exclusão, a extremo noroeste, já evidenciados nos Box Map.

Em relação a utopia de qualidade de vida, dos aspectos ambientais, é possível constatar regimes espaciais definidos de clusters de Alta-Alta exclusão social bem delineados em quase todo o município, para os indicativos de domicílios com precário abastecimento de água e instalação sanitária (AAPrecp e ISPrecp). Especificamente, podemos ressaltar as regiões de Papillon, Paraíso, Buriti Sereno, Expansul, Zona da Mata e Zona Rural. Como já era de se esperar, este fator reflete diretamente nos clusters significativos de elevada exclusão, dos Moran Map, verificados nestas mesmas regiões ((Figura 6).

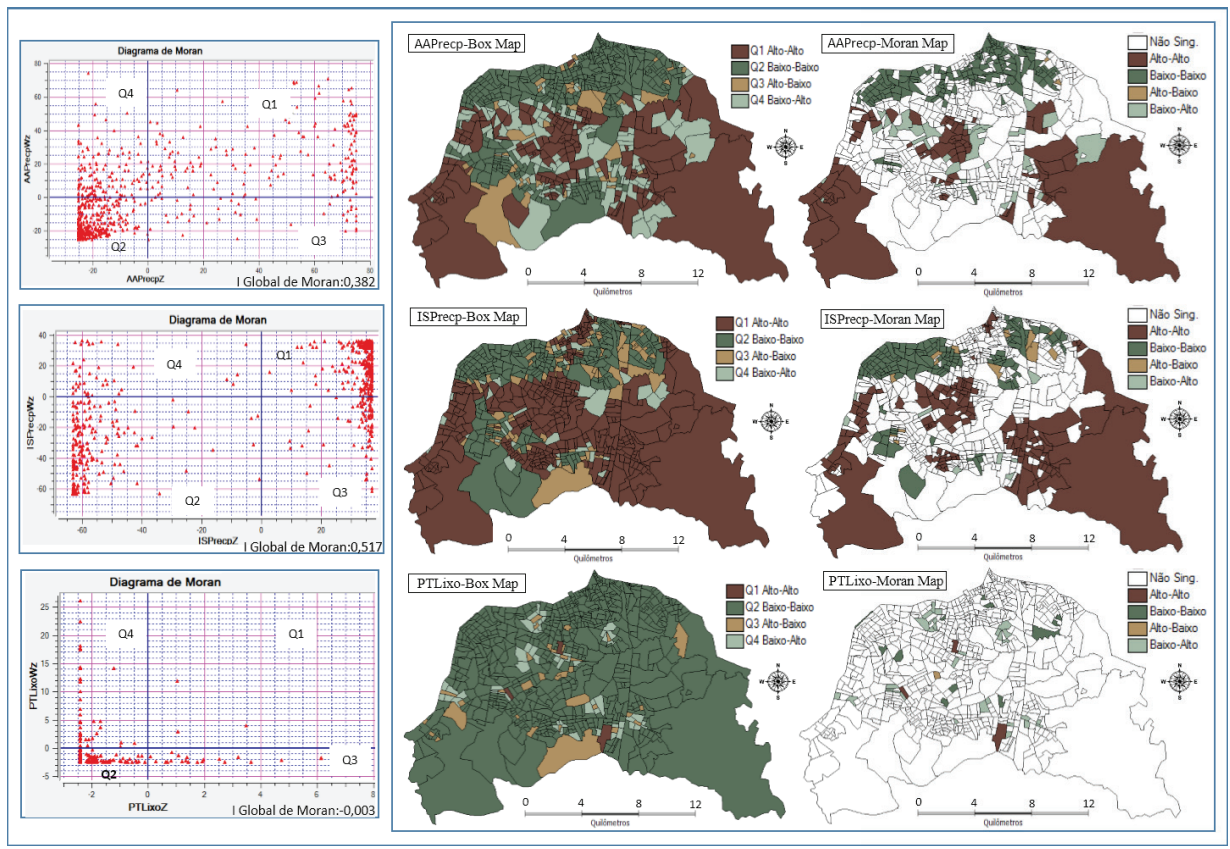

Figura 6. Índices de autocorrelação espacial dos indicativos da qualidade de vida ambiental.

Nas variáveis de AAPrecp e ISPrecp podemos observa ainda, algumas áreas de conglomerados censitários de Baixa-Baixa exclusão social, coincidentes apenas com as duas regiões administrativas mais desenvolvidas do município, Garavelo e Vila Brasília. Já no Box Map representativo dos domicílios com precário tratamento de lixo (PTLixo), é bem nítido o predomínio da classe de Baixa-Baixa exclusão, por todo o município, reafirmando seu papel preponderante, de variável que mais contribui para amenizar a desigualdade social.

A Figura 7 apresenta os resultados da análise espacial para os índices de conforto domiciliar e equidade. Os Box Map revelam a predominância da classe de 
Alta-Alta segregação, nas regiões da Zona da Mata, Zona Rural, Expansul e Papillon, que apresentam os maiores índices de domicílios sem pavimentação (Q1). Já na questão da densidade habitacional, a concentração e verificada nos domicílios pertencentes as regiões da porção central de Aparecida de Goiânia, ao longo do Anel viário e na porção sudoeste do município. Para o fator equidade feminina, o Box Map mostram a predominância de índices negativos, Baixo-Baixo (Q2) e Baixo-Alto (Q4), percentual de mulheres chefes de família, em quase todo o município.

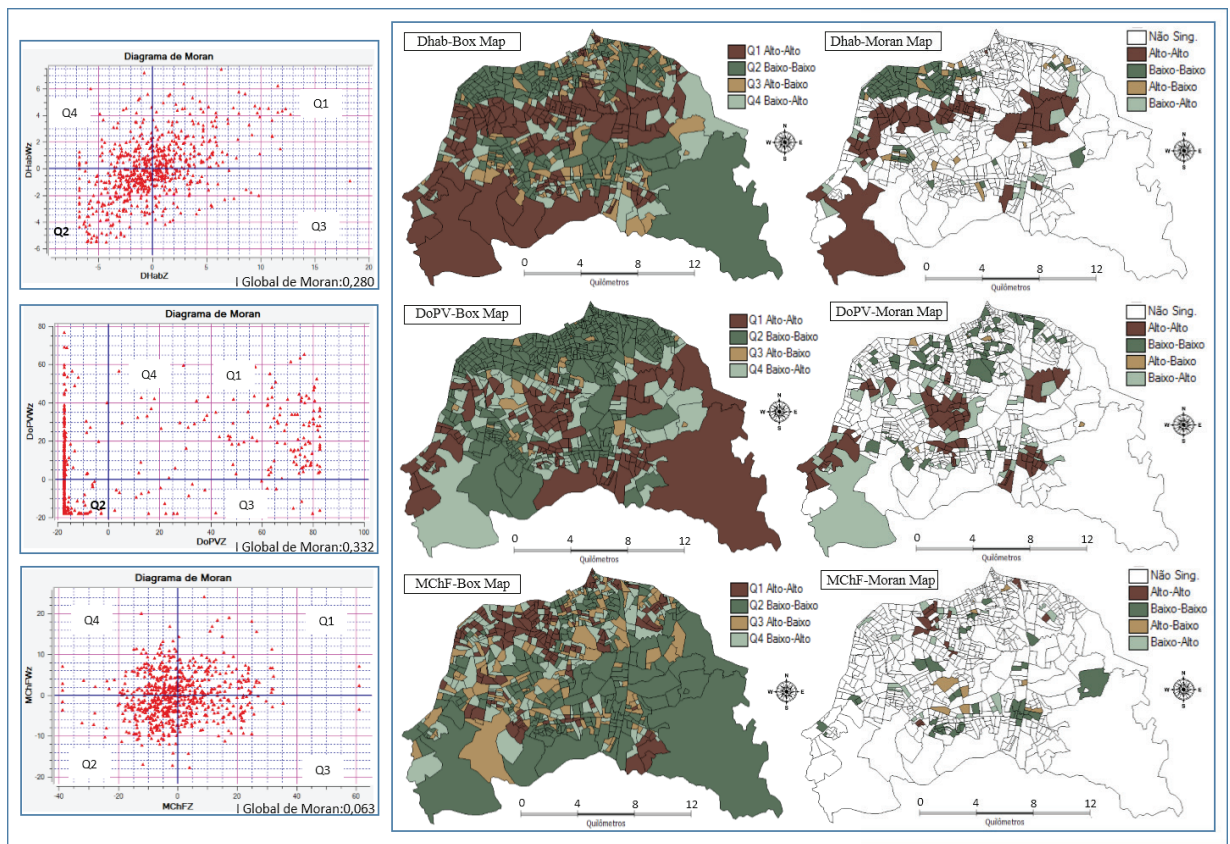

Figura 7. Índices de autocorrelação espacial dos indicativos do conforto domiciliar e equidade.

Por fim, a partir da definição dos conglomerados urbanos foi possível calcular o índice-síntese das utopias, computada para cada fragmento censitário. Assim, como produto final obteve-se por meio da aplicação de álgebra de mapas, o mapa síntese, derivado da ponderação da somatória das variáveis que contribuem para a exclusão social, subtraída, das variáveis de longevidade e mulheres chefes de família, que contribuem para a inclusão social (Figura 8).

Em suma, o Box Map apontado na Figura 8, confirma a desigualdade socioterritorial bem definida de Aparecida de Goiânia. O mapa da correlação de todas as utopias, indica um predomínio de clusters de inclusão social (Q2), nas porções nortenoroeste do município, ou seja, na zona conurbada com Goiânia. Já os clusters de exclusão social (Q1) concentram-se nas áreas periféricas da região sudoeste, Expansul e em alguns trechos junto ao anel viário. 


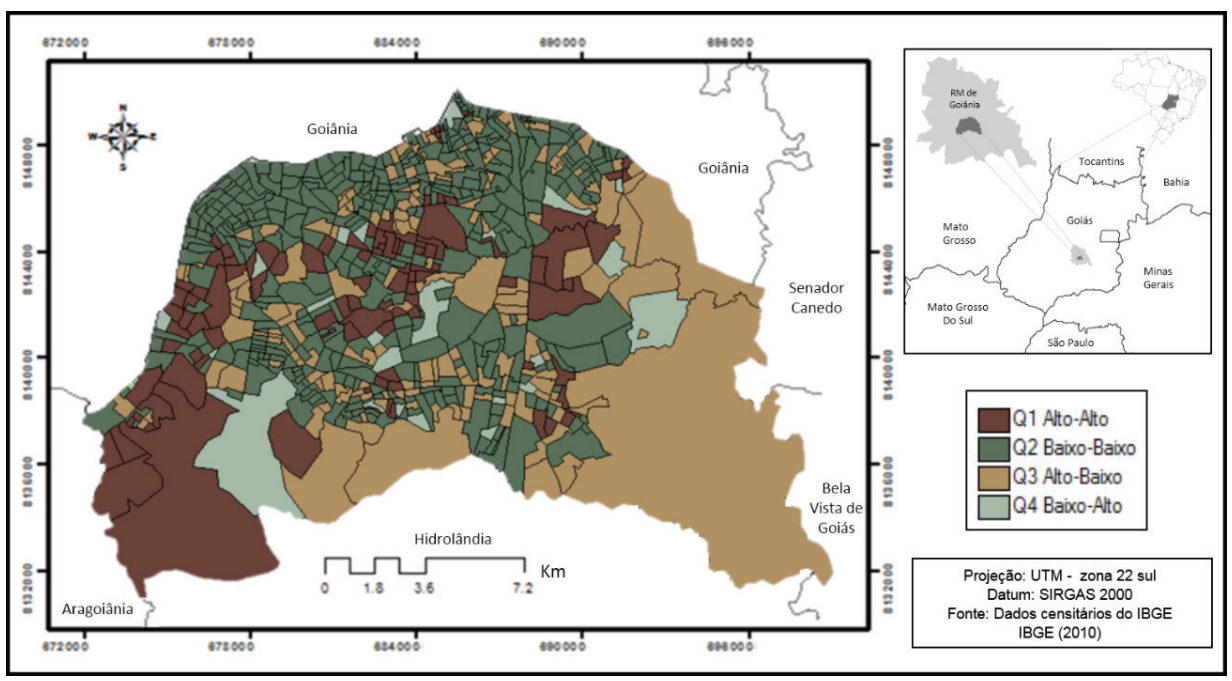

Figura 8. Índice de exclusão/inclusão social - Box Map síntese das utopias investigadas.

Vale ainda frisar, que o pico de inclusão social nas porções norte-noroeste e a própria tendência da exclusão social, aumentando no transecto, direção centro-periferia, corroboram para as afirmações de Cirqueira Pinto (2009), quando o autor aponta que Aparecida de Goiânia pouco se relaciona consigo mesma e muito se relaciona com a sua capital. Ressalta-se aqui, seu status de cidade periférica e caótica, na medida que o município é subordinado a um arranjo funcional atrelado a sua capital e, ao mesmo tempo, apresenta uma estrutura interna fragmentada, múltipla e desigual.

\section{Considerações finais}

O mapeamento de áreas de clusters tanto de alta como de baixa exclusão social, revelam que Aparecida de Goiânia possui aglomerados de fragmentos censitários, bem definidos, configuradores da segregação socioterritorial, do espaço intraurbano aparecidense. Como a questão da segregação socioterritorial, tendem a ser um fenômeno geograficamente distribuído e, desigual, sua detecção pode ser auxiliada por técnicas de análise espacial em plataformas de SIG.

Essas ferramentas computacionais, cada vez mais, têm se mostrado possuidoras de um grande aparato de manipulações de dados censitários. Seus produtos finais, ou seja, os mapas e diagramas gerados, tornam-se uma alternativa viável para o entendimento dos indicativos de exclusão/inclusão social. Neste sentido, são ferramentas promovedoras do retrato das necessidades especiais de cada setor censitário, revelando a real situação da população existente. 
Este fator é validado na medida que as utopias analisadas variam em função das características intrínsecas de cada fragmento urbano, evidenciando assim, as peculiaridades internas da cidade. A própria detecção e espacialização dos clusters de exclusão/inclusão social, reforça a visualização de que a desigualdade socioterritorial em Aparecida de Goiânia, está diretamente conectada as áreas conurbada do município com a sua capital, da polarização de pequenos polos industriais e comerciais e, de suas regiões periféricas.

É importante destacar, que a aplicação do índice de Moran contribuiu para a análise da dependência espacialização e mapeamento dos dados, no ranking dos setores censitários, incorporando informações geográficas não somente de cada setor isolado, mas a influencias de seus vinhos para determinação dos clusters, das desigualdades socioterritorial. Assim este método verifica não só a localização, mas também, o grau de cada utopia, entre o setor censitário e seus vizinhos que estão na mesma situação.

Não podemos ainda esquecer que as regiões que apresentaram fragmentos censitários considerados estatisticamente significantes, na correlação espacial, com suas áreas vizinhas, é um bom indicativo de que o fragmento relava uma maior especificidade em sua variável determinante. Esta resposta, enfatiza a necessidade de ações políticas governamentais, que considerem as diferença interna, do espaço intraurbano de cada unidade mapeada.

Para finalizar, é importante lembrar que a representação espacial em SIG, é uma abstração da realidade, estando subordinada à eficácia da técnica metodológica empregada e da precisão dos dados utilizados. Por outro lado, é evidente que sua capacidade de manipular uma diversidade de dados de natureza censitária, fazem com que os ferramentais do SIG possibilitem uma visão mais apurada das questões sociais de uma cidade. Desta forma, seus resultados, podem ser considerados como um diagnóstico síntese e revelador de aglomerados de setores urbanos, que apresentam altos ou baixos índices da problemática em questão.

\section{Referências}

ANSELIN, Luc. Exploratory Spatial Data Analysis in a Geocomputational Environment. In: LONGLEY, P. A.; BROOKS; S. M.; MCDONNELL, R.; MACMILLIAN; B. Geocomputation: a primer. Chichester, John Willey, 1998, p.77-94.

APARECIDA DE GOIÂNIA, Prefeitura de. PD - Plano Diretor de Aparecida de Goiânia: desenvolvimento para o futuro - diagnóstico. Aparecida de Goiânia, 2014. Disponível em: $\quad<$ http://pdaparecida.com.br/noticias/diagnostico-da-realidade-de-aparecida-degoiania-ja-esta-disponivel-para-download/> . Acesso em abril 2015.

BOAVENTURA, Deusa M. R.; ASSUNÇÃO, Lorena S. A (re). Construção do espaço urbano de Aparecida de Goiânia. Revista Brasileira de Desenvolvimento Regional. Blumenau, v. 1, n.2, p.213-235, 2013. 
CÂMARA, Gilberto et al. Territórios Digitais: as novas fronteiras do Brasil. Revista Estudos Avançados, São Paulo: USP, 2005. Disponível em: <http://www.faed.udesc.br/ arquivos/id_submenu/1423/territorios_digitais.pdf >. Acesso: março de 2015.

CÂMARA, Gilberto et al. Análise espacial e geoprocessamento. In: DRUCK, S.; CARVALHO, M. S.; CÂMARA, G.; MONTEIRO, A. V. M. (eds). Análise Espacial de Dados Geográficos. Brasília: EMBRAPA, 2004.

CÂMARA, Gilberto; MONTEIRO, Antônio. Territórios digitais urbanos. In: ALMEIDA, C. M. de; CÂMARA, G.; MONTEIRO, A. M. V (org.). Geoinformação em Urbanismo: cidade real x cidade virtual. São Paulo: Oficina de Texto, 2007. cap.1, p. 34-53.

CEM - Centro de Estudo da Metrópole. Base de dados. Disponível em: <http://www. fflch.usp.br/centrodametropole/>. Acesso: novembro de 2014.

CIRQUEIRA PINTO, José. A. Periodização de Aparecida de Goiânia: da forma embrionária às novas funcionalidade no espaço fragmentado. Boletim Goiano de Geografia. Goiânia, v. 29, n.1, p.87-106, 2009.

ESTATUTO DA CIDADE: Lei n ${ }^{\circ}$ 10.257, de 10 julho de 2001, e legislação correlata. $2^{\circ}$ ed., Brasília: Câmara dos Deputados, Edições Câmara, 2009. Disponível em: <bd. camara.gov.br/bd/.../estatuto_cidade_2ed.pdf>.Acesso: maio de 2015.

GENOVEZ, Patrícia; MONTEIRO, Antônio; CÂMARA, Gilberto e FREITAS, Corina. Indicadores territoriais de exclusão /inclusão social: geoinformação como suporte ao planejamento de políticas sociais. In: ALMEIDA, C. M. de; CÂMARA, G.; MONTEIRO, A. M. V (Org.). Geoinformação em Urbanismo: cidade real x cidade virtual. São Paulo: Oficina de Texto, 2007. cap.3, p. 64-85.

HUMACATA, Luis M. Análisis exploratoria de datos socio-espaciales mediante gráficos interactivos: aproximación univariada y bivariada aplicada a la provincia de Buenos Aires (Argentina). Geografía y Sistemas de Información Geográfica (GEOSIG). Revista digital del Grupo de Estudios sobre Geografía y Análisis Espacial com Sistemas de Información Geográfica (GESIG). Luján, año 2, nº . 2, p.135-163, 2010

IBGE-Cidades. Censo Demográfico Brasileiro 2010. Instituto Brasileiro de Geografia e Estatística. 2010. Disponível em: <http://www.cidades.ibge.gov.br/xtras/home.php>. Acesso: abril de 2015.

KREMPI, Ana Paula. Explorando Recursos de Estatística Espacial para Análise da Acessibilidade da Cidade de Bauru. 2004. (Dissertação de Mestrado). USP. São Carlos: Escola de Engenharia de São Carlos, 2004.

ROMAN, Frederico; CÂMARA, Gilberto; MONTEIRO, Antônio. Territórios digitais urbanos. In: ALMEIDA, C. M. de; CÂMARA, G.; MONTEIRO, A. M. V (Org.). Geoinformação em Urbanismo: cidade real x cidade virtual. São Paulo: Oficina de Texto, 2007. cap.1, p. 34-53.

SANTOS, Lucas Maia dos. A produção do espaço intra-urbano de Aparecida de Goiânia e a dinâmica metropolitana de Goiânia: de 1960 a 2000. 2008. Dissertação (Mestrado em Geografia) - Instituto de Estudos Socioambientais, UFG, Goiânia, 2008. 
SANTOS, Milton. Por uma Outra Globalização: do pensamento único à consciência universal. São Paulo: Record, 2000.

VITTE, Antônio Carlos. Modernidades, territórios e sustentabilidades: refletindo sobre qualidade de vida. In: VITTE, Claudete Silva Castro de; KEINERT, Tânia Mezzomo (Org.). Qualidade de Vida, Planejamento e Gestão Ambiental: discussões teóricometodológicas. Rio de Janeiro: Bertrand Brasil, 2000. cap.4, p.111-122.

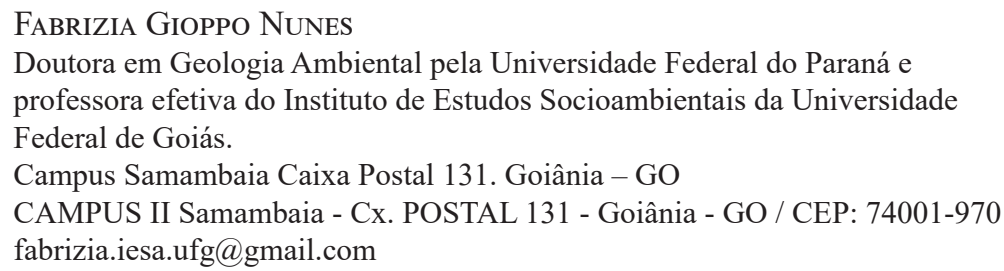

Recebido para publicação em setembro de 2016

Aprovado para publicação em dezembro de 2016 